\title{
A Conceptual Framework for Investigating the Impact of the Internet on Corporate Financial Reporting'
}

\author{
Jason Zezhong Xiao. Cardiff University. UK \\ xiao@cardiff.ac.uk
}

\author{
Michael John Jones. Cardiff University. UK \\ jonesm12@cardiff.ac.uk
}

\author{
Andy Lymer. University of Birmingham. UK \\ a.lymer@bham.ac.uk
}

\begin{abstract}
This paper develops a conceptual framework of the impact of the Internet on corporate financial reporting on the basis of the issues and concerns elicited through an open-ended questionnaire survey of 17 UK-based experts in the Internet/accounting. These experts were drawn from academics, accounting firms, business companies, regulators, and users of accounting information. The diverse views expressed by our experts enable us to construct a four dimensional framework on the nature of change in financial reporting (content, form or both), the role of the Internet (as problem solver, problem creator or both), the determinant of change (technology, non-technology, or both) and the pace of change (little or no change, progressive change and radical change). These dimensions and sub-dimensions are combined to form a "perspective surround' enclosing a conceptual matrix of 81 different possible scenarios. The framework provides a basis for mapping existing and future studies on Internet reporting and constructing scenarios of future Internet-based financial reporting.
\end{abstract}

Key words: Change, Corporate Reporting, Financial Reporting, Future Trends, Internet.

\footnotetext{
${ }^{1}$ This paper is part of a more extensive research project sponsored by the Centre for Business Performance of the Institute of Chartered Accountants in England and Wales. A descriptive and practitioner-oriented report on the project has been published by the sponsor. Apart from theorization and orientation, this paper also differs from the report in content and structure.

Data availability: Data used for this paper can be obtained from the first named author.

Acknowledgements: We are very grateful to the Centre for Business Performance of the Institute of Chartered Accountants in England and Wales for funding this research.
} 


\section{INTRODUCTION}

Within a short period of less than 20 years, the Internet has grown from an essentially academic facility to the backbone of the information superhighway. It is now widely used in homes, schools, universities, business companies, and public sector organizations for a variety of purposes. The on-line population reached $60 \%$ in the US, 55\% in the UK, and 52\% in Australia by August 2001 (NUA.COM, 2002). The total global online population was just under $7 \%$ in 2000 (eTForecasts, 2001), but is expected to reach $22 \%$ by 2007 (ClickZ.com, 2004). The Internet has also become an increasingly attractive market place with estimated worldwide business to business e-commerce amounting to US \$1.4 trillion in 2003 and US \$2.7 trillion in 2004 (eMarketer, 2003).

The Internet appears particularly pertinent to financial reporting. First, it is a global network which makes physical and national boundaries less meaningful and thus provides a seamless information delivery channel. With the advent of World Wide Web, it supports powerful hypertext and hypermedia presentations. In addition, the Internet is capable of integration with other information and communication technologies. In particular, its convergence with database technology opens many opportunities for improving financial reporting. Indeed, the Internet is increasingly used for corporate reporting (Lymer, Debreceny, Gray $\&$ Rahman, 1999). Moreover, the Internet has been used to develop large scale data depositories, such as Electronic Data Gathering, Analysis and Retrieval (EDGAR) which has been used by the Security Exchange Commission (SEC) in the US to receive and disseminate corporate filings since 1995 (see www.sec.gov).

Given the growing importance of the Internet and its evident relevance to financial reporting, it is important to investigate the future impact of the Internet on financial reporting. As the business world becomes increasingly dynamic, academics and practitioners have called for improvements in financial reporting (e.g., AAA, 1991; Jenkins Report, 1994; Wallman, 1995). Furthermore, the accounting profession is anxious to gain an insight into its future position in an Internet environment (e.g. Elliott Report, 1996).

Reflections on the future of the Internet-based financial reporting are commonplace. These reflections, unfortunately, suffer from a number of problems. First, few studies are grounded in theory or attempt to theorize. Second, most 
studies adopt a technological imperative perspective and largely neglect nontechnological factors (Xiao, Dyson \& Powell, 1996). Third, most reflections are based on personal observations which are limited in both scope and depth. Finally, existing reflections are generally made without reference to a specific time frame. It is, therefore, not only difficult to evaluate these conjectures properly, but also problematic to use them as the basis for policy making.

As a first step to address these issues, this study formulates a framework consisting of four dimensions of perspectives: the nature of change in financial reporting (content, form or both); the role of the Internet (as a problem solver or a problem source); the main determinant of change (technology, non-technology or both) and the pace of change (little or no change, progressive change and radical change). This framework emerges from the opinions on Internet reporting by 2010 solicited through an open-ended questionnaire answered by a group of 17 UK experts in accounting and/or the Internet drawn from accounting firms, business companies, regulatory bodies, universities, and users of accounting information. The framework provides a point of departure for studying the future of Internet reporting and a conceptual approach to synthesising existing and future studies of the topic. The framework also encourages the generation of multiple scenarios of future Internet reporting which we believe are useful for policy making.

The remainder of the paper is organized as follows. In section 2, we summarize the existing studies of Internet-based financial reporting. Section 3 presents our research methodology. This is followed in section 4 which presents a variety of expert opinions which form the empirical basis for constructing our conceptual framework. These views are initially structured into six broad themes: general trends in information and financial reporting; impact on the preparers; impact on users; impact on auditing and assurance; impact on regulation, standards and control; and technological trends. Section 5 formulates a conceptual framework for future research on the basis of Section 4. This consists of a four-perspective 'surround' and a conceptual matrix. The final section concludes the paper.

\section{LITERATURE REVIEW}

Financial reporting on the Internet has become an increasingly attractive research topic. Prior studies are mainly descriptive or reflective. The descriptive 
studies survey the current state of financial reporting on the Internet (e.g., Lymer, 1997; Deller, Stubenrath \& Weber., 1999; Asbaugh, Johnstone \& Warfield, 1999). For example, Deller et al. (1999) find that over 95\% of top 100 U.S. companies have a Web site with at least $92 \%$ presenting their annual reports. The corresponding figures are $85 \%$ and $74 \%$ for top 100 UK companies and $71 \%$ and $65 \%$ for top 100 German companies.

Based on such theories as agency theory, signaling theory, or innovation diffusion theory, a number of more recent studies have examined the determinants of Internet-based corporate disclosure (ICD) (e.g., Ettredge, Riachardson \& Scolz (2002; Debreceny et al. 2002, and Xiao et al. 2004). Many determinants have been tested, usually based on the studies of hardcopy corporate disclosures. These include firm size, leverage, industry, listing status, profitability, auditor type, and tangible assets. Ashbaugh et al. (1999), Craven and Marston (1999), and Ettredge et al. (2001) find that larger U.S. and U.K. companies are more likely to provide financial information on the Internet. Pirchegger and Wagenhofer (1999) find that whereas firm size and profitability affect the ICD of Austrian companies, they do not affect German companies' ICD choices. While studying the determinants of voluntary ICD in the U.S., Ettredge et al. (2002) makes a distinction between disclosure of items that are mandated by the SEC, and those not required by regulation. The findings indicate that the former are associated with company size and information asymmetry between the company and investors whereas the latter vary with company size, information asymmetry, demand for external capital, and disclosure reputation. However, the study only examines the content aspect of disclosure.

Debreceny et al. (2002) find that voluntary adoption of ICD in 22 countries is associated with company size and listing on an U.S. stock exchange, but not with leverage, risk, and Internet penetration in the countries. In contrast to Ettredge et al. (2002), this study distinguishes between presentation format and disclosure content. It finds that the level of technology and disclosure environment are associated with presentation format, but not with content. However, the study does not distinguish between the disclosures of mandatory versus non-mandatory items.

Xiao et al. (2004) study ICD in China. They find that there is a significant and a positive relation between mandated and voluntary disclosure. They further show that the presentation format of ICD is associated with the employment of a 
Big-5 auditor and whether the firm is in the information technology industry, while a negative association exists between profitability and the voluntary disclosures. Voluntary ICD is positively and significantly associated with the proportion of legal person ownership, but not with ownership by domestic private investors, foreign investors and the state. In addition, the proportion of independent directors has a positive relation with presentation format, voluntary disclosures, and the availability of English Web pages.

In most companies, Internet reporting basically replicates existing hard copy reporting (Bury, 1999). An exception is Microsoft whose Web site provides multiple-GAAP and multiple language financial information as well as data analysis tools (see www.microsoft.com). Despite the growing use of the Internet for disseminating accounting information, there is little evidence to suggest that Internet-based information has become increasingly useful for users (Taylor, 1998; Barker, 1999). Prior studies identify many problems associated with Internet reporting, such as increased information overload and the difficulty in locating specific Web site and information items (Debreceny \& Gray, 2001), the omission of potentially important information in the traditional annual report (Ettredge et al., 2001), and the difficulty in distinguishing between audited and non-audited information (Bury, 1999).

There has also been a good deal of "crystal-ball gazing" into the future of Internet reporting, mostly comprising the 'personal' reflections of informed experts. These reflections are largely based on the observed characteristics of the Internet and its advantages over traditional media used for financial reporting: the adoption of a client-server model, the use of digital technology, the capability of integrating with other technologies, the allowance of real-time as well as delayed communications, the use of hypertext/hypermedia, and the Internet's capability for supporting one-way, two-way and multi-way communications on a local, national or global scale. For example, Lymer (1997) summarizes the advantages of the Internet for financial reporting as being cheap, quick, dynamic and flexible.

One prediction often repeated in the literature is that the Internet will enable companies to provide a whole range of additional non-financial information in their annual reports (for example, Green \& Spaul, 1997). In turn, this may cause information overload. However, the Internet is typically an environment that provides solutions to the problems it creates. In this case, hypertext technology, 
search engines, and intelligent agents will ease the task of information retrieval and may alleviate the problems of information overload (Aoun, 1996; Upton, 1998; Baldwin \& Williams, 1999).

Another widely held reflection is that the Internet will, in time, permit real-time financial reporting as well as on-line periodic financial reporting (Green \& Spaul, 1997). Meanwhile, Kogan, Sudit \& Vasarhelyi (1998) and the CICA (1999) believe that the Internet will facilitate continuous process auditing in an environment of on-line real-time systems.

By providing a powerful dissemination tool, Lymer (1997) argues that the Internet may facilitate "events" reporting ${ }^{2}$ (Sorter, 1969) and that database reporting ${ }^{3}$ (McCarthy, 1982; Cushing, 1989) may become a reality. Furthermore, various commentators advocate a free access model. For example, Wallman (1997) reflects that the Internet and database technology will provide users with free access to corporate databases, although others consider "selective access" more realistic (Schneider \& Bowen, 1997; Beattie, 1999). Similarly, Spaul (1997, p.13) envisages a "corporate dialogue" via the Internet which allows all stakeholders "immediate access to a broad range of internally generated corporate information and to more informal materials, such as technical research reports and media reports compiled by third parties. From this base data they will have the power to construct their own reports."

Schneider \& Bowen (1997) believe that the Internet makes customized financial reporting possible, offering the benefits of timeliness, finer data and flexibility. Prima facie, the trend of these proposals appears to be an increased customer focus. Bury (1999), however, argues that the standardization of financial information on the Internet will become necessary. Jensen \& Xiao (2001) argue that the Internet enables both standardization and customization. They propose

\footnotetext{
2 "Events" reporting focuses on reporting business events, rather than on reporting aggregated financial data. When no prior knowledge exists of users' information needs and decision models, Sorter (1969) argues that the task of data aggregation should be left to users. Thus, financial statements should be constructed in sufficient detail so that users can deduce underlying events (Dunn \& McCarthy, 1997).

${ }^{3}$ Database accounting aims to provide users with a database of information from which they can extract event data at various levels of focus and aggregation. It expands 'events' reporting in the context of database technology, although the two approaches differ in orientation. Events reporting involves the preparation of less aggregated financial reports whereas database accounting focuses more on the storage and maintenance of data at their most primitive levels (Dunn \& McCarthy, 1997).
} 
customization around a standard report as the way forward. They believe the peer-to-peer (P2P) technology and XML together will permit the achievement of joint customization among reporting companies, information intermediaries and end-users of information. The ICAEW (1998) develops such a model from a stakeholder perspective consisting of a core corporate report supplemented with other reports (i.e., a financial and economic report, a people report, a sustainability report and supply chain report).

Debreceny, Gray \& Barry (1999) envisage that the Internet will facilitate a type of "agglomerated" analysis of financial information. That is, users will use Internetbased financial and other information to screen companies to "rank investments, raise green or red flags, or enhance shareholder democracy". For some the future of the traditional hard copy annual report is gloomy. "There might be a paper version in the future, but nobody's going to use it" (Bury, 1999, p. 29). Gowthorpe \& Flynn (1997, p. 68) make a similar prediction: "Companies are due, as a result of Internet technology, to report far more fully and frequently than ever before, stakeholders of all kinds will be both more informed and empowered and the old fashioned glossy corporate report is due for its long-awaited demise."

The eXtensible Business Reporting Language (XBRL) initiative (www.XBRL. org) has attracted researchers' attention. Debreceny \& Gray (2001) believe XBRL will help alleviate current difficulties in locating Web sites and information items therein whereas Jensen \& Xiao (2001) envision XBRL as a necessary means for achieving distributed file sharing among reporting companies, information intermediaries and end-users in a peer-to-peer networking environment.

Reflections on the future of on-line corporate reporting abound. The work of the American Institute of Public Certified Accountants (AICPA) and the Financial Accounting Standards Board (FASB) illustrate the seriousness with which the accounting profession is examining these speculations (see Jenkins Report (1994), Elliott Report (1996), FASB's FauxCom project ${ }^{4}$ and the Business Reporting Project (FASB 2000). The Canadian Institute of Chartered Accountants (CICA) also released a report (Trites, 1999) discussing the current and future prospects for

\footnotetext{
${ }^{4}$ A web-based financial reporting model developed by the FASB on the basis of the AICPA's Business Reporting Model developed in the Jenkins Report (1994). The Fauxcom Web site is accessible at http://wwww.rutgers. edu/Accounting/raw/fasb/.
} 
online financial reporting. This report highlights the need for customizable reporting by recommending a move away from general purpose, traditional financial reports and 'GAAP' to focused reporting and regulation for different user groups.

These reflections are useful in raising awareness of the potential of the Internet for financial reporting. However, most of these reflections lack theorizing and are inspired by the technological features of the Internet and give little consideration of non-technological factors (for example, social, cultural, organisational and legal factors) that affect the adoption of the Internet for financial reporting. In addition, most prior reflective studies are based on personal observations. Finally, none of the studies specify a time horizon against which predictions are made. As a consequence of these problems, most predictions or reflections in the literature are biased, fragmented and unspecific. This paper represents a tentative attempt to address these problems.

\section{RESEARCH METHODOLOGY}

Twenty UK experts in accounting and/or the Internet participated in our study. These experts represent the widest possible range of constituencies involved in corporate reporting including: academics, auditors, preparers, regulators, and users. The single criterion of inclusion was that the person was a recognized expert in accounting and with good knowledge of the development and/or application of the Internet. The experts were not randomly selected, but were chosen following several steps. First, the total number of experts needed and the number for each constituency were determined. An initial list of experts for each constituency was then composed on the basis of the researchers' and the Institute of Chartered Accountants in England and Wales' (ICAEW) Centre for Business Performance's knowledge of the key individuals currently involved in examining Internet reporting in the United Kingdom. The short-listed experts were then contacted by phone and all of them agreed to participate. A questionnaire was distributed to the experts in January 1999 and 17 of them replied by the end of May 1999. The other three experts failed to respond despite our best efforts (including sending reminder letters and making repeated phone calls). A summary of our respondents is given in Appendix 1. 
The experts were requested to answer an open-ended question: ${ }^{5}$ What will be the trends by 2010 in external financial reporting on the Internet and what are their implications? The experts were thus encouraged to present their own opinions in an open, unstructured, way without being influenced or guided by the researchers. No specific guidance was thus provided by the researchers.

The written responses from the experts were analysed in the following way. First, one of the researchers read the responses several times depending on the length and level of elaboration. Key trends and factors were highlighted and noted during this process. These trends and factors were then pooled but tagged so that the experts who made the specific comments could be identified and the original remarks quoted if necessary. Second, the researcher then grouped the trends and factors and placed each under a heading (or theme). At the third step, a second author joined the categorization process which was repeated several times. This process enabled us to derive six broad categories of issues: general trends in information and financial reporting; impact on the reporting company; impact on users; impact on auditing and assurance; impact on regulation, standards and control; and technological trends. Within each issue we identified several key themes. These themes are not necessarily consensual. Wherever appropriate, we illustrate the expert views using direct quotations. To contextualize the comments, we categorise each expert (for example, Academic A and User B). Based on the debates under these themes, we extracted four key dimensions: the nature of change, the role of the Internet, determinants of change, and pace of change. We also delineated sub-dimensions for each of the four dimensions.

A major strength of our methodology lies in the fact that the participants were all experts. Appendix 1 shows that all the experts occupy senior positions within their particular organizations. For example, five were corporate finance directors and two were members of the UK's Accounting Standards Board. These individuals could, therefore, speak from positions of knowledge and authority. In addition, because an open-ended question was asked, the views expressed by our experts were not biased by the researchers' preoccupations. Our experts thus provided an informed insight into future developments on Internet reporting.

\footnotetext{
${ }^{5}$ Another question was asked of the immediate trends in Internet reporting as reported elsewhere.
} 
The strengths of our methodology also inevitably created associated weaknesses. First, a geographical bias may exist because our experts were UKbased. However, most experts were familiar with international developments in accounting and Internet. In addition, one expert was from the then International Accounting Standards Committee with a strong background of US and international accounting and Internet-based financial reporting.

Second, the sample was small which necessitates caution over the generalisation of findings. However, the aim of this paper was to obtain a range of expert views, however diversified, on Internet reporting by 2010, rather than undertake a statistical analysis on the basis of a large sample. We were primarily interested in charting the issues, concerns and alternative scenarios and using these as an initial basis for formulating a framework of perspectives on future Internet reporting. Finally, there may be a sample selection bias. The sample was not randomly generated because our study required experts rather than a random sample. The sample is thus biased towards expert views. Nevertheless, expert views should add credibility to the findings.

\section{EXPERT RESPONSES}

In this section, we present important issues and concerns identified by the experts. The purpose is to show the existence of a variety of views that can be used as an empirical basis for constructing a conceptual framework in the next section. The different views that were obtained from our experts are discussed under six main headings (current trends, impact on preparers, impact on users, impact on auditors, impact on regulators and technology trends). Although the views were elicited at a particular point in time, they relate to on-going, persistent and pervasive themes within Internet reporting. The issues are constantly evolving overtime and the pace of change is uneven varying not only between countries, but also between companies. The expert views thus form an appropriate basis from which to develop a conceptual framework. ${ }^{6}$

\footnotetext{
${ }^{6}$ In some cases, our experts' predictions have already been prevailing or fully adopted. We draw attention to such current developments in the footnotes.
} 


\subsection{General trends in information and financial reporting}

There was a consensus that access to the Internet will increase greatly by 2010 although the exact extent of increase varied across experts. A conservative estimate was that the majority of the population in the developed countries would have access to the Internet by 2010 . The most optimistic view was that " $100 \%$ of the population in developed countries would be able to access the Internet and the access is at least as wide as the telephone and TV is today" (Preparer D). These represent different perspectives on the pace of technology adoption.

Furthermore, the experts believed that, by 2010, the Internet would be the major medium for communication between a company and its stakeholders. For example, Preparer A commented "the Web site will be the first contact with the company as commonplace as picking up the phone today and will therefore have effective "meeting and greeting' skills...." The design and content of Web sites will therefore become increasingly important over this period. An increased demand for financial information was identified. In particular, the demand for information in electronic form would increase greatly, particularly as a result of the increasing unification of voice, data and image telecommunications (the integration of telephone, computer, radio and television: the so called "information super-highway"). This increased demand would not only create resource pressures on companies, but also would require them to re-examine the way they manage price sensitive information. The experts predictions on both the use of the Internet as a major medium for communication and the demand for financial information reflect a technology deterministic view, that is, technology such as the Internet will drive changes (Xiao et al., 1996).

The experts saw corporate reporting as a subset of electronic commerce. By 2010, electronic commerce was expected to be used for the majority of business transactions, debts would be collected immediately in the form of e-cash, and cash flow problems arising from slow payments would become a historical phenomenon. Company share prices and share dealings would be available at each company's Web site. ${ }^{7}$ In fact, stockbrokers would lose market share to each company's own

\footnotetext{
${ }^{7}$ Online share dealing is increasing rapidly. In the UK, there were about 38,300 online share-dealing accounts in 1999 (BBC, 1999). However, companies selling their own shares online have not yet become widespread. Ellis \& Everard Plc (2001) became the first UK company to experiment with online share trading in 1999.
} 
direct dealing unit and would function as added value service providers rather than execution brokers. The experts also believed that e-commerce and e-cash would need policing to prevent abuse. This would create additional assurance or attestation work for accountants or IT specialists. Thus, some experts considered the Internet as a problem solver by improving communication, meeting user information demands, and speeding up transactions while others perceived it as a problem creator by increasing resource pressures and posing additional security and assurance issues.

\subsection{Impact on the preparers}

Our experts discussed a number of issues. These included (a) the increased uses of the Internet by reporting companies; (b) the extent of the impact on financial reporting, (c) the future of the hard copy annual report, (d) the possibility of free access via the Internet, and (e) the provision of raw data. Each of these issues is discussed below.

\subsubsection{Increased uses of the Internet}

According to our experts, the Internet would be used for a wide range of purposes on the assumption that the Internet is capable of solving many financial reporting problems. These would include the dissemination of corporate information, such as press releases and the statutory filing of company information with regulatory and listing authorities such as the Securities and Exchange Commission in the USA. ${ }^{8}$ It would also be used to distribute video messages from management on a regular basis. ${ }^{9}$ This would counter the inability of managers to meet the increasing demands by users for face-to-face meetings. However, many other uses were also possible:

\footnotetext{
${ }^{8}$ Apart from the SEC's EDGAR discussed in the text, from 1 January 1997, SEDAR (www.sedar.com/homepage en.htm) and Companies House Direct disseminates online information filed by Canadian and UK companies respectively (see http://www.companieshouse.gov.uk/services/). Specialist Web sites have been created to cater for financial reporting needs. These include Hemmington Scott (www.hemscott.net), Corporate Reports (www. corpreport.co.uk) and Companies' Annual Reports On Line (CAROL, www.carol.co.uk/).

${ }^{9}$ This practice has already started. Cisco Systems' Web site (Www.cisco.com), for example, webcast the president's letter contained in the 2001 annual report of the company. Vodafone Group Pld also webcast its preliminary announcement for the year ended March 2001 (www.vodafone.com).
} 
The majority of relevant information to shareholders will be displayed on the Net. Linked Web sites will enable the shareholder to buy and sell shares directly and proceeds/costs will be immediately shown on his/her personal banking Web sites. AGM's voting will also be electronic via the Net and the AGM proceedings can be watched live on the video down link (Preparer C). ${ }^{10}$

\subsubsection{Extent of the impact on financial reporting}

Two contrasting views on the pace of change emerged: a conservative view and a radical view. The conservative scenario suggested that financial reporting would not be radically different in 2010 from the current system except for more corporate Web sites, more on-line users, and more information dissemination. By contrast, the radical view suggested that Internet reporting would be very different. There would be "self-evident differences in presentation, communication and dissemination, with substantive differences in scope, frequency and, in particular, the extent of cross-referencing of underlying information" (Regulator C). One particular development singled out was an increasing use of video data and increasing interactivity in financial reporting (Regulator E).

Another prediction was that the Internet would be used to present a multidimensional view of company activities: "At present it is very difficult to relate information on a company obtained from, say, the business pages of a newspaper to that obtained as a potential customer. However, if a company recognises that diligent users will not confine themselves to information that is aimed directly at them, its Web site will provide a multi-dimensional view of its activities, explaining the relationship between the company's products or activities on the environment and its financial position and performance" (Regulator D).

Several other trends in Internet reporting were identified. In particular, the Internet would encourage more frequent reporting and even enable real-time

\footnotetext{
${ }^{10}$ Shareholders of many U.S. companies now vote online. These include Bell \& Howell (www.bellhowell.com) (Corrigan, 1997), Hermes Investment Management Limited (www.hermes.co.uk. Online AGMs already take place in many companies such as AT\&T, Bell \& Howell, Barrick Gold, Dell Computer, Genzyme, and Microsoft (Judd, 2000). The UK Investor Relations Society broadcasted its AGM live on the Internet (Judd, 1998).
} 
reporting. ${ }^{11}$ This would make "the concept of the accounting period less important than at present" (Academic B). In general, "there will be pressure on preparers to get everything done a lot quicker" (Academic A). In addition, companies would provide, on the Internet, more forward looking as well as historical information, clearly distinguishing the audited information from the non-audited information. The experts also envisaged that companies would link share price movement information to financial information and non-company information (Regulator A). Finally, on measurement, Regulator F believed that "data (will be) available in multiple measurement bases - historical cost and fair value are no longer as either/or options (sic)."

\subsubsection{The future of the hard copy annual report}

A spectrum of different views existed on this issue ranging from no change through continued existence to complete replacement. Academic B anticipated no change: "The paperless office will prove to be a chimera due to social obstacles to genuine acceptance of computer technology." Preparer A believed that hard copy reports and Internet reporting would co-exist. Other experts presented several more radical scenarios. One possibility was that hard copy reports would only be provided on demand and at a cost. Another alternative view was that real-time updating of information on the Internet would make hard copy reports obsolete or unreliable. A key driver for Internet reporting would be the cost savings resulting from the cessation of the production and distribution of hard copy reports. E-mail distribution would be markedly cheaper. User B summed this up: "The annual report will disappear - all the research shows that the document is out of time, too costly, too cumbersome and too expensive and too difficult to get hold of to manipulate."

Most of the experts believed that by 2010, on-line reporting would be the norm and companies would place all their financial reports on the Web. For example, Preparer E remarked, "The norm by 2010 for external financial reporting should

\footnotetext{
${ }^{11}$ Several companies, such as Cisco Systems, Dell Computer, and Motorola, have implemented a system whereby accounts can be closed so as to provide information to executives in as little as four hours (Caplan, 2001). However, no company has attempted real time external financial reporting although some companies such as Ford Motor Company (www.ford.com) updates their share price every 15 minutes.
} 
be that there is no paper based set of accounts, except perhaps one copy on which the Chief Executive and Finance Director could append their signatures. All external communication will be electronic." There was a strong feeling that the publication of external financial reports on the Internet would become effectively $100 \%$ the norm, certainly for listed and large companies. Indeed, Regulator D predicted that the London Stock Exchange would introduce a requirement to this effect by 2004.

The above debate is interesting because our experts not only held different views on the pace of change, but also held two different views on the factors that might determine the pace of change. Advocates of technological determinism considered technological factors as the driver for change while supporters of non-technology determinism saw economic (including cost savings) and social factors (e.g., social obstacles to technology acceptance) as the driving force.

Although hard copy reports might disappear, the standardized annual report was predicted to remain in electronic format. This standard report was thought to provide an essential point of reference and its credibility would be enhanced by independent audit. Regulator D, for example, thought that Adobe Acrobat (or a similar structured presentation technology) could be used to replace hard copies, while retaining the advantages of the annual report:

It would seem odd for companies to discard these advantages, and so the most likely development will be for companies to publish their annual reports on the Internet, and supplement it with further information. In the main the additional information would not be a different presentation of the information contained in the annual reports. It is much more likely to be additional - either addressing areas where disclosure in the annual report is not required, or seen as appropriate, or providing the same information at a much greater level of detail.

This raises an interesting point: there may be different types of change, medium, presentation format, or content. 


\subsubsection{Free access via the Internet}

The experts' views on the free access model (Spaul, 1997; Wallman, 1997) ${ }^{12}$ were enlightening. Only Preparer D was slightly sympathetic to this model. He envisaged a scenario of equal access in which Internet meetings between company managers and analysts would be open to users thus allowing equal access to the same information at the same time ${ }^{13}$.

In fact, users already have free access to information disclosed in the public domain including much of the information published on the Internet. However, the free access model implies access to information not already made public. In this sense, the general consensus of our experts was to dismiss this free access model for reasons of commercial confidentiality, fear of litigation, user ignorance, users' inability to use the information, information overload, and corporate reluctance to give away more than the minimum amount of information ${ }^{14}$. User A was also critical of the technologically-driven view: "Presentation of accounting information may change but quality of information at any depth is unlikely to change - firms will not give away more data than they have to by regulations and statutes however easy it is to do so on-line and electronically. Any changes that have occurred will be very gradual not radical in terms of extra data provided and how it is provided. Companies won't be making more data available just because they can use electronic means." Thus, for this expert, it is important to distinguish content from presentation format/medium when discussing the impact of the Internet on financial reporting. Regulator $\mathrm{C}$ concurred: "The law will never require the provision of direct access to aspects of the company's accounting records, because to do so would breach confidentiality and make competition impossible."

A more realistic scenario was that the reporting company would retain control over information dissemination. Auditor A favoured a differential access model:

\footnotetext{
${ }^{12}$ The free access model is described by commentators using different terms, for example, "access accounting" (Wallman, 1997) and "corporate dialogue" (Spaul, 1997). It may be characterized as the provision of raw data via the Internet that is freely accessed and used by users to formulate their own reports.

${ }^{13}$ Some companies already do this. For example, a French company, Saint-Gobain, webcasts management meetings with individual shareholders, or with analysts/investors www.saint-gobain.com)

${ }^{14}$ Not all users have access to information that companies upload onto the Internet. Some information can only be viewed by employees or managers through an intranet, while some other information can be accessed by business partners (but not other external users), via an extranet. In addition, technical problems prevent some users from accessing published information.
} 
different types of user would be given access to different levels of information and this differential access, combined with real-time reporting, will help achieve "demand pull" 15 . This scenario is consistent with Beattie's (1999) two-tiered model for corporate data, with each tier accessible by external users and internal users, respectively. Yet another possibility is the catalogue publishing model where the company provides external users with a menu and allows them to choose from the list (Jensen \& Xiao, 2001). The above debate again illustrates a range of different views on the pace of change in the control of access to information and two contrasting views on the drivers of change: technology determinism and nontechnology determinism.

\subsubsection{Provision of raw data}

Traditionally, companies provide highly aggregated information. However, many researchers recommended more disaggregated information. For example, Sorter (1969) called for a re-examination of the value of an "events" reporting model, while Cushing (1989) and Dunn \& McCarthy (1997) both advocated a database accounting model. The advent of the Internet makes such calls more realistic (Schneider \& Bowen, 1997).

Our experts differed on the degree of potential disaggregation. ${ }^{16}$ Regulator D believed that the provision of raw data was not useful for users: "Users are best served if information is arranged and classified in a way that is useful for them." Academic B believed that financial information would be less aggregated, with users being more self-reliant in the analysis and synthesis of data. Companies would not, however, provide information in a raw data format. In this expert's opinion, these benefits were questionable for both preparers and users:

... And it seems reasonable to me to question the premise that more, and more frequently available, information would necessarily be desirable.... Companies may baulk at the provision of large amounts of timely data into the public domain; deterrents such as cost, access by competitors to commercially sensitive

\footnotetext{
${ }^{15}$ Demand pull refers to large archives of information stored on distributed servers directly accessible by information users. The goal of a demand pull information dissemination system is to make a large volume of data available to a large number of users with user discretion on its use.

${ }^{16}$ For instance, Microsoft www.microsoft.com provides segmented data on line together with analysis tools.
} 
information, potential legal responsibility in respect of errors and compliance with relevant regulation, are likely to figure large in companies' assessment of the risks.... Users do not use, and often do not know how to use, the level of information which is currently provided.... There is evidence that even serious and well-informed users (taking the analyst group) do not and cannot absorb all the information which is currently made available to them; they tend to deal with it on an exception basis only, examining a company's detailed accounting information only where they are alerted of a problem.

By contrast, Academic A predicted that "Companies will have started to place their financial reports in a raw data format. This will enable analysts and other interested parties to manipulate the data and carry out far more complex analysis currently available."

Thus, while some experts predicted that Internet technology will drive companies to disclose disaggregated information, others disagreed and argued that non-technological factors would make such disclosure either undesirable or unnecessary.

\subsection{Impact on users}

Our experts speculated on a range of user-related issues such as the uses of the Internet, the move towards "demand pull" information, access to multidimensional data, information overload and technical assistance.

\subsubsection{Uses of the Internet}

Our experts expected users to use the Internet in an increasingly sophisticated manner, including data monitoring (or screening), searching, downloading, and manipulation (such as "what-if" analysis). Users would have vastly improved access to increased information and be able to interrogate the data available. Moreover, they would search data and do "what-if" analysis across companies with ease, as well as having "intelligent" computers programmed to monitor, download and manipulate relevant Internet data. Academic A painted a picture of an "events" reporting approach, and believed that users would enjoy far greater relevance and timeliness of information. On the basis of the raw data available, users would be able 
to manipulate and carry out more complex analysis than now. However, Academic A suggested that users would tend not to trust the information as much as they do currently. This would create demands for new assurance services and new markets for added value information filtering services. Although Academic B dismissed the idea of raw data provision, this expert argued that the standardized format would enable users to screen a large number of companies to produce exception reports. ${ }^{17}$ This would become a more important feature of primary data analysis.

In addition to financial analysis and interpretation, users were expected to use the Internet for other purposes, such as to attend online meetings between company management and financial analysts or institutional investors as well as online or broadcast shareholder meetings. They also suggested that online voting would become common with some impacts on the democracy of large organizations where smaller investors would be able to become more vocal.

\subsubsection{Demand pull information}

Our experts observed that the Internet was being used by some reporting companies for image management. However, they expected, by 2010, that users would use the Internet as a conduit to "pull" information from companies in ways which suit them rather than ways defined by the reporting company. Regulator A summarized this as "demand pull for information, Web sites created in response to shareholder, stakeholder, and lender needs." This demand pull scenario was partly based on the free access model which, as discussed previously, was not shared by all our experts. This change, if realized, would be a shift from preparer-dominated reporting to user-oriented information dissemination.

\subsubsection{Access to multidimensional data}

Internet reporting by 2010 would be characterized by its multi-dimensional nature. "The annual report... will be enhanced by company news, financial briefings (video) on line and 'almost real-time' delivery of financial information using multimedia/video tools... by trend analysis across the life of the company

\footnotetext{
${ }^{17}$ Databases such as EDGAR provide the basis for such large scale screening by users assisted by software products such as EDGARSCAN ${ }^{\mathrm{TM}}$ http://www.pwcglobal.com/gx/eng/ins-sol/online-sol/edgarscan/s
} 
- period on period - and across sectors.... the annual report will need to .... be bundled with other corporate information as part of the corporate communication message (User B)."

User B saw two implications of such a multi-dimensional view. First, financial information would become more useful when related to non-financial information. Second, when provided in context, financial information was more likely to be understood by non-expert users of accounting information. This expert raises an intriguing point, that is, change in the content of financial disclosure is facilitated through a change in the medium. In other words, the electronic format enables integration of financial with non-financial information and contextual information.

\subsubsection{Information overload and technical assistance}

Some experts worried that the publication of multiple dimensional data and raw data would cause information overload. However, others believed that more sophisticated search and navigation tools would help users search in more effective ways than is currently possible. In addition, more sophisticated software, such as intelligent agents (Aoun, 1996; Baldwin \& Williams, 1999) would monitor and download relevant information for users. In short, the Internet was considered by some as a source of problem, while by others as a problem solver.

User B predicted a narrowing of the skill gap between sophisticated and nonsophisticated investors. While many more tools would be designed to help novices understand and interpret accounts, there would be little extra help for experts as they would already have what they need. Expert users would perhaps benefit from improved presentation of some types of data as accounts become more targeted to non-expert users. However, whether companies would truly present data with non-experts in mind would very much depend on the development of the user oriented reporting focus.

\subsection{Impact on auditing and assurance}

In general, our experts expected auditors to use the Internet to their advantage. Preparer $\mathrm{C}$ envisaged that auditors would have their own Web sites containing company-specific comments or audit opinions linked to company Web sites. In 
addition, our experts discussed auditors' attitudes towards Internet reporting, the scope of audit, the need for continuous auditing, increased risk of fraud, and the future of the audit profession.

\subsubsection{Auditors' attitudes}

Our experts believed that auditors, in general, would remain reactive, contrary to the more pro-active role called for by some commentators (e.g. Debreceny \& Gray, 1999). Auditors would prefer the status quo because they are basically risk averse and they are likely to resist a model of freely available disaggregated information via the Internet. Regulator C, for example, foresaw an evolutionary perspective built upon the continued existence of the current auditing model of systems-based audit and risk analysis: "Current audit practices will no doubt have to change, but not as radically as some people seem to think. The independent opinion on the financial statements will still be a safeguard for the public. It will still be supported by risk analysis and review of the systems to counter the risks." Thus this expert held a gradualist view on audit change that might take place in the Internet environment. By contrast, Academic B held a more conservative view. She believed "old habits die hard" and auditors would, therefore, be in favour of preserving the status quo. Furthermore, the audit profession might act as a brake on radical developments in Internet reporting:

Auditors tend to be naturally conservative because, fundamentally, they operate on the basis of minimizing the risks to themselves at all times. New forms of reporting characterized by frequency and a data orientation, rather than an information orientation, would present considerable threats to auditors and are therefore likely to be resisted. At the Big Five level their influence over events may be considerable; they are likely to form a sizeable constituency in any committees set up by the profession to consider the direction of regulation, and they have long experience of effective lobbying.

\subsubsection{Scope of audit}

Our experts debated the scope of audit. Two broad views existed. Academic A believed that all reports on the Internet would be attested although few attestations would have the style of a current audit report. By contrast, Regulator $\mathrm{C}$ anticipated 
that "The external auditor's report will not extend to the full content of a company's Web site, but will be confined to those elements of it which are specifically labeled as audited from a financial point of view." Focusing on the content of auditing, this debate again saw two contrasting views on the pace of change.

\subsubsection{Continuous auditing}

In general, auditors would move away from interim and annual audits to rolling continuous audits (see Kogan et al, 1998; CICA, 1999). "Auditors will neither be the driver nor the brake on the comprehensive use of the Internet for financial reporting. However, with more financial information being published and faster, traditional audit techniques for interim and annual audits will no longer be appropriate. Auditors need to develop continuous audit techniques" (Preparer E).

\subsubsection{Increased risk of fraud}

Our experts perceived the risk of fraud as an increasing problem. Regulator F believed that auditors would be exposed to greater audit risks because Internet reporting provides more opportunities for fraud. Electronic information is transitory. Its distribution and quality is, therefore, hard to police. As a result, auditors would focus even more on systems and less on data. Here the Internet was clearly seen as a problem source.

\subsubsection{Future of the audit profession}

Our experts foresaw a significant erosion of accounting as the key professional competence for auditing. Traditional audit services would be supplemented by assurance services such as Webtrust ${ }^{18}$ seals that provide assurance of the underlying systems as a basis for public confidence. Although on-line attestation would become a major industry, it is likely to be dominated by information technology specialists.

\footnotetext{
${ }^{18}$ WebTrust (available at http://WebTrust.org) is a service jointly developed by the Canadian Institute of Chartered Accountants (CICA) and the American Institute of Certified Public Accountants (AICPA). It enables consumers and businesses to purchase goods and services over the Internet with the confidence that vendors' Web sites have historically met high standards of business and information privacy disclosures, transaction integrity and information protection as assessed by the providers of the seal.
} 
Other non-accounting professionals, such as environmentalists, might audit other aspects of non-financial information on a company's Web site. Third party seal of assurance would be needed for different audits. Thus, the Internet was seen as both creating problems (threats) and providing solutions (opportunities).

Indeed, a new specialist industry would arise consisting of publicly accredited experts in the certification of information security management and accounting software and of experts in risk evaluation and control of electronic commerce. The need for rationalization of this range of assurance might lead accounting firms increasingly to employ a variety of experts. Technological sophistication was thus considered to create a new professional discipline.

\subsection{Impact on regulation, standards, and control}

The Internet was predicted to be of great importance to regulators. An interesting view offered by Preparer $\mathrm{C}$ is that regulators would have their own Web sites (linked to the Web sites of the companies concerned) where they would place company-specific comments. This has parallels to the independent auditors' Web site discussed earlier. The main concern of our experts, however, is on the possible changes that Internet reporting would bring to regulation and standard setting. They discussed a range of related issues, including the need for new regulations and controls, specific regulatory requirements, difficulties in regulation, and the globalization of regulation.

\subsubsection{Need for new regulations and controls}

Two different views existed on the content and pace of change. Some experts foresaw no need for additional regulation. For example, Regulator D believed that existing controls over the improper publication of information on paper would be applicable to much Internet-based financial information, although the extent of application to the Internet would need further clarification. Thus, there would be no need for radically different controls. Even if some new controls are introduced, Regulator D saw it as important that they did not inhibit the freedom of management to publish information they believe to be useful.

Most experts, by contrast, however, implicitly assumed that new regulations and controls would be necessary. However, there were different perspectives concerning 
the ways regulatory changes would take place. Some adopted a technologically deterministic perspective: regulatory changes will be driven by the power of the Internet. These experts regarded the existing regulatory framework as a constraint to Internet reporting and envisaged a need for new regulation to permit flexible financial reporting based on the capabilities of the new technology.

Other experts, however, adopted a non-technologically imperative view. For example, Regulator B anticipated that legislation "may well alter accounting requirements, particularly for small and medium sized companies. However, he believed the development of companies legislation, rather than the use of alternative means of communication, would govern accounting disclosure and audit requirements." For Academic B, a substantial scandal would increase the likelihood of the more formal imposition of regulation on Internet reporting. Preparer E believed that new accounting and auditing standards would be needed for Internet reporting and auditing. The expert acknowledged, however, that standard-setting would be a slow process because of the time it takes to achieve a consensus and because of structural problems (such as the stately pace of the working party, the need to consult widely, and the lack of Parliamentary time devoted to regulation).

\subsubsection{Specific regulatory requirement}

Several experts predicted specific developments by 2010 , for example:

- The law would require companies to publish specific company information on the Internet

- Mandatory quarterly and even monthly reporting (but not real-time reporting) would be required

- Although technologically feasible, companies would not be required to abandon the hard copy annual report completely

\subsubsection{Difficulties in regulation}

Even if Internet reporting was standardized, and more specific regulation developed and imposed, monitoring of compliance would be difficult. Several 
regulators believed that regulatory enforcement would be increasingly difficult as Internet reporting becomes more sophisticated. One difficulty stems from the possibility that anyone can distribute information to users unnoticed by regulators. There was also a call for a more conceptually-oriented approach to standard setting as technology was likely to advance more quickly than standards.

\subsubsection{Globalization of regulation}

Focusing on form of regulation, our experts expressed different opinions on the issue of national versus global regulation. Regulator D believed that it would be impossible for individual countries to control and regulate Internet reporting. His solution was that implicit user scepticism towards Internet-based information would help to allay most concerns and thus explicit global regulation would be unnecessary. By contrast, Regulator F was a strong believer in global regulation. He predicted the convergence of national generally accepted accounting principles (GAAP) around a single global GAAP as well as the emergence of a single global presentational standard and format for annual and interim reports, with national additions. Other experts believed that although standards and regulation would remain nationally based, the individualized global regulatory framework would be further advanced.

\subsection{Technological trends}

Advances in information technology would facilitate the development of Internet reporting. A number of important developments were cited. First, there would be increasing integration of voice, data and image telecommunications (the development of a true 'information super-highway'). Second, data security technology would increasingly become more sophisticated. The two most likely forms would be encryption and fixed format (e.g. Adobe pdf) plus web-based documents (e.g. HTML or XML) as dual distribution mechanisms. Third, intelligent agents would be used widely on the Internet, taking advantage of greater bandwidth made available by developments in the infrastructure of the Internet. In addition, companies would provide information services on a pay-by-use basis using thinclient applications. This approach would enable sophisticated software to be made available on an ad-hoc basis. Companies would create new types of Web sites with 
user-oriented data in response to users' needs. ${ }^{19}$ Within companies, new internal controls and procedures using the Internet would be developed to help manage stakeholder issues. Finally, the design of Web sites would become increasingly important as the key 'window' into the company.

\section{A CONCEPTUAL FRAMEWORK OF INTERNET- BASED CORPORATE REPORTING}

The expert views on the themes and issues reported in the preceding section can be synthesised into four main dimensions: the extent of change, the role of the Internet, the determinants of change and the pace of change. We articulate these dimensions into a conceptual framework which can be used to map existing and future studies on Internet reporting, to assess the speed and extent of actual developments of Internet reporting, and to generate alternative scenarios of future Internet reporting. We call these four perspectives our conceptual surround.

\subsection{The nature of change}

The above debates suggest that it is important to distinguish between content from form when discussing change in financial reporting. Changes may take place in the form, content or both of financial disclosure, auditing and regulation. It is possible for content, but not form, to change. Conversely, form, but not content, may change. Another possibility is that both content and form could change. This distinction is consistent with the approaches adopted by some recent empirical studies on Internet-based financial reporting such as Debreceny et al. (2002) and Xiao et al. (2004).

There were, for example, several views on the future survival of the traditional hard copy annual report. One view by some experts was that the Internet would become the major medium of communication between preparers and users. On the other hand, other experts believed that the hardcopy financial reports would survive. A third views was that even when the medium has changed from hardcopy

\footnotetext{
${ }^{19}$ Some companies such as Microsoft (http://www.microsoft.com) have experimented with financial reporting based on multiple currencies, language and accounting standards. A number of companies (such as Morgan Stanley and Reuters) are using XBRL-based financial reporting.
} 
to electronic media, the standardised annual report content would remain. Some experts believed that the presentation medium might change, but that the quality and types of information might not. Moreover, there was a view that a change in the content of financial disclosure might be facilitated through a change in the medium, suggesting that there might be some interaction between content change and medium change.

Turning to the impact of the Internet on auditing, the debates also distinguished different types of change. For example, several different views existed on the scope or content of audit. Some argued that the status quo would remain while others argued that the scope would be greatly expanded to include Web-based disclosures although the exact nature of which information would be audited and which would not remain unclear. On the form of auditing, there was a view that there would be a move away from periodic auditing to continuous auditing.

\subsection{The role of the Internet}

The Internet may be conceived as a means of addressing existing problems by enabling or facilitating alternative financial reporting methods (problem solver) or as a cause of additional problems (problem creator or problem source). On the one hand, our experts examined whether the Internet provides a solution to many existing problems in financial reporting such as the lack of timeliness, the lack of customization and the provision of over aggregated information (AICPA, 1994). For example, they discussed whether the Internet would allow free access to corporate databases, provision of raw data, and real time reporting. On the other hand, our experts recognized that the Internet would create additional problems or exacerbate existing problems, as manifested in their debate over such issues as global accounting regulation, the scope of auditing, how to audit Internet-based data, and how to distinguish audited and non-audited information, and the need for new assurance services. For some issues (for instance, information overload and Web-based assurance), our expert suggested the Internet as both a problem creator and solver. Overall, our experts collectively saw the Internet as a doubleedged weapon, at least at a conceptual level. 


\subsection{Determinants of change}

As to the perceived main determinant of change, our experts were divided into three groups. The first group saw Internet technology as the driving force of change in financial reporting. This view can be termed technological determinism which equates technological progress and social change, assuming that technology inevitably leads to social change (Howcroft \& Fitzgerald, 1998). According to this view, financial reporting is mainly a technical issue. Current problems of financial reporting are caused by the lack of computing and communication power. The Internet is thus seen as an ideal solution to many of these problems. By contrast, the second group held a non-technology deterministic perspective. They believe that social, cultural, legal, political and behavioral factors are the main causes for change and technological developments reflect this (Edge, 1994; Dutton, 1996). According to this view to which these experts implicitly subscribe, financial reporting is a political process (Solomons, 1978) with spectacular economic consequences (Zeff, 1978) and accounting knowledge and practices are socially and organizationally determined and constructed (Burchell, Clubb, Hopwood, Houghes, \& Nahapiet, 1980). For example, our experts generally dismissed the free access model for reasons of commercial confidentiality, fear of litigation, user ignorance, users' inability to use the information, information overload, and corporate reluctance to give away more than the minimum amount of information. The issue of the need for global regulation can be used to illustrate the differences between the two perspectives. The experts who held a technology deterministic view (e.g., Regulators A \& F) expected Internet reporting to create an overwhelming demand for global regulation and the Internet to provide the solution by developing such technologies as eXtensible Business Reporting Language (XBRL). Therefore, a set of global accounting regulations would prevail. Those other experts who took a social deterministic view (e.g., Academic B), however, considered it impossible to reconcile political, social and cultural differences. For them, global regulation was impossible.

The third group adopted a contingency view. This bridges technological determinism and social determinism by considering both technological and nontechnological factors (Xiao et al., 1996). According to this perspective, there are many drivers of, or barriers to, change. The impact of one factor depends on, or interacts with, those of the others. To illustrate this perspective in the context of 
global regulation, although the application of the Internet in financial reporting will generate a great demand and Internet technology may provide technical help, the success of global accounting regulation depends on factors such as internationalisation of capital markets and political negotiations between national, regional and global regulators. Taking account of both technological and nontechnological factors, a likely scenario may be national and regional customization around a set of global regulations (e.g., Regulator F). An alternative scenario would be the co-existence of national and global regulation (e.g., Preparer B).

\subsection{The pace of change}

Three different views existed: little or no change (conservatism), progressive change (gradualism) and rapid change (radicalism). Take the need for change in the scope of auditing as an illustration. The conservative view (e.g., Academic B) was that there would be no or little change; only financial statements would be audited. The progressive experts (e.g., Regulator C), however, believed that apart from the traditional financial statement audit, some other financial and non-financial information on the Web would be audited (such as environmental auditing). By contrast, the radicals (e.g., Academic A) believed that the whole Web site would be audited. Similarly, in discussing frequency of reporting, the conservatives (e.g., Regulator D) believed that current annual and semi-annual reporting would sufficient. From a progressive perspective, however, Academic B and User B believed that there would be more timely information provision (including quarterly and monthly reporting) whereas the radical view (e.g., Regulator F) foresaw real time reporting.

\subsection{Towards a framework of future Internet reporting}

The three dimensions are now combined to form a conceptual framework for predicting the future impact of the Internet on financial reporting (see Figure 1). This consists of a four perspective 'surround' endorsing our conceptual matrix. According to this framework, the prediction of future Internet reporting needs to address the following four questions: 
- What will change (content, form, or both of financial disclosure, auditing and regulation)?

- Will the Internet potentially be a problem solver, creator or both for the main issues?

- How much change will take place (no or little change, some change or total change)?

- Is the extent of change driven by the Internet, other non-technological factors, or both?

As can be seen from Figure 1 our conceptual framework consists of four perspectives surrounding (The Perspective Surround) our conceptual matrix. Each of the four perspectives has three dimensions. As each perspective can interact with any other perspective of any other dimension, there are in effect 81 potential combinations for these four perspectives $(3 \times 3 \times 3 \times 3)$. One of these eighty-one potential combinations is thus content (extent of change), radical (perspective on change), problem solver (perspective e on role of the Internet) and technologicaldeterministic (perspective on determinants of change). Thus, for example, one might believe that the hard copy annual report would change quickly (pace of change) to electronic format (extent of change) with the Internet facilitating this change (role of Internet as problem solver) and this change would be technologically driven (determinant of change). Thus, our four perspectives are molded into the conceptual matrix.

Before we discuss the uses of this framework, it is important to examine the problem of orthogonality. There is a need to consider whether the four dimensions materially overlap. In statistical testing, for example, serious multicollinearity will lead to redundant variables. However, slight collinearity is permissible. Across our variables, we identify very little overlap. There is, however, interaction among the dimensions. For example, one could take a technology deterministic view while considering the Internet as a problem solver, thus predicting a radical change. Similarly, one could take a technology deterministic view while assuming the Internet as a problem creator, thus predicting a minimum change. 


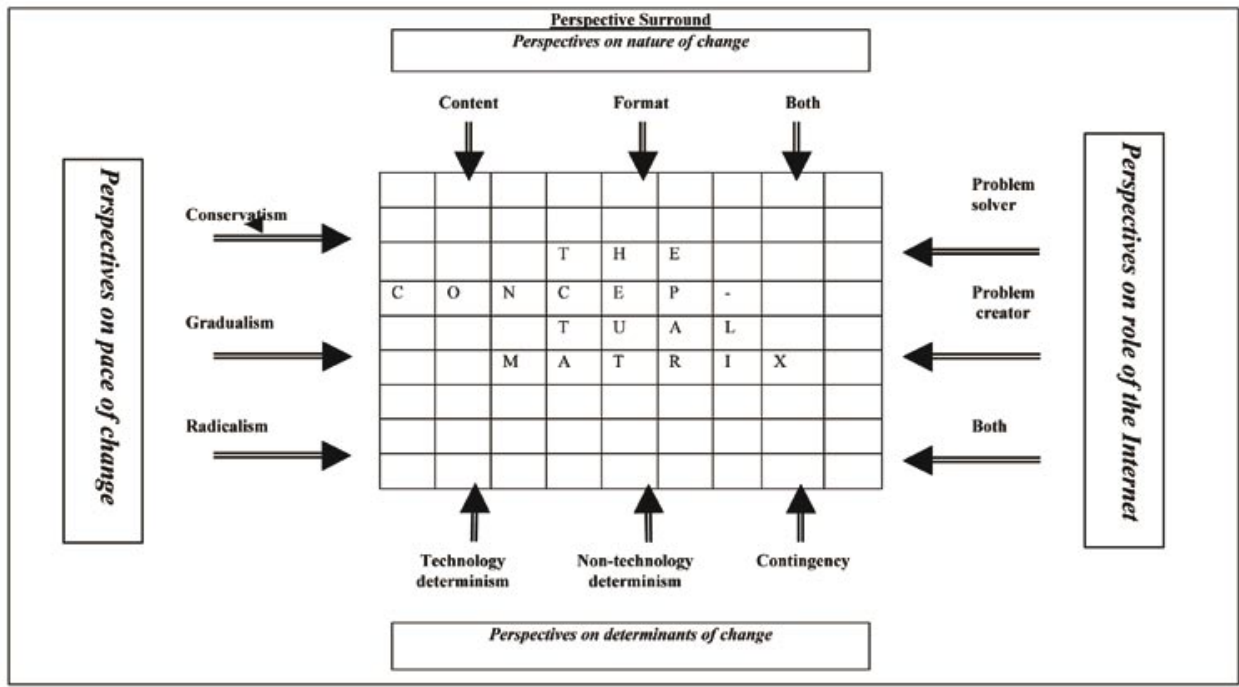

Figure 1. A Conceptual Framework on the Impact of the Internet on Corporate Reporting Note: Each of the four dimensions has three perspectives. As a perspective of one dimension can interact with any perspective of another dimension, there are in effect 81 outcomes in our conceptual matrix.

Our experts debate on the problem of reporting aggregated information or raw data is illustrative. The level of information aggregation relates to both the presentational form of information and the content of information. In a sense, it is a form because it involves different levels of aggregation (total assets versus specific intangible assets). However, aggregated information usually obscures information and may make information less useful. By contrast, a certain level of disaggregation reveals different types or additional information (such as revenues and profits by line of business, geographic region). This is an issue to which the Internet was perceived as a potential solution (a problem solver). The underlying problem was whether to change the level of disclosure. Conservatives (e.g. Academic B) believed that there is already too much detail, users are unable to handle details and thus there should be no change. The progressive view (e.g., Regulator D), however, believed that companies would be willing to supplement the annual report with more detailed information and able to provide raw data to some users such as business partners. By contrast, radicals (e.g., Academic A) suggested that raw data should be disclosed so that all users can formulate their own reports.

If there is a need for change, then what will be the main cause of change and what is the pace of change? Technology determinists believed that the Internet 
would permit two scenarios. Either the Internet would be widely used and allow mass users to access corporate databases, thus permitting online provision of raw data (e.g., Academic A and Preparers D \& F). Or alternatively, Internet adoption would be uneven and the technology would not be available to many users and companies, thus preventing companies from disclosing information in raw data format (e.g., User B). By contrast, the non-technology determinants (e.g., Academic B) believed that social, organizational and behavioral factors would determine whether raw data is provided. In general, they considered that companies would not provide raw data because of users' inability and reluctance to deal with detailed data, confidentiality issues, the cost of providing and utilizing the data. According to the contingency perspective (e.g., Regulator D), however, whether to disclose raw data would depend on the type of data and user, and Internet availability to both users and firms.

In addition, the dimensions and sub-dimensions can used to chart studies on Internet financial reporting. To illustrate, some studies focus on the change in content of financial disclosure (e.g., Ettredge et al., 2002), others focus on changes in presentational form of financial reporting (e.g., Frank, 2003), and still others consider both content and form (Debreceny et al., 2002). Some studies take a technology deterministic view (e.g., Spaul, 1997), others consider nontechnological factors as more deterministic (e.g., Edge, 1994), and still others would take a contingency perspective (e.g., Xiao et al., 2002). Some studies mainly focus on the Internet as a problem solver (e.g., Bury, 1999; Green and Spaul, 1997), some focus on the Internet as a problem source (e.g., Debrecency and Gray, 1999), while others would consider it as both a problem solver and creator (e.g., Howcroft and Fitzgerald, 1998). Some studies predict progressive changes (Xiao et al. 2002) while other studies predict radical changes (e.g., Wallman, 1997).

\section{SUMMARY AND CONCLUSION}

On the basis of the diverse experts views on issues and concerns relating to Internet reporting by 2010, we have formulated a conceptual framework for investigating the impact of the Internet on corporate financial reporting. The framework consists of four dimensions. The first dimension suggests that a change could take place in content, form, or both of financial reporting. The second dimension - the role of the Internet - recognizes the Internet as a double-edged 
weapon; not only as a potential means of alleviating some existing problems in financial reporting but also as a creator of additional problems. The third element focuses on the pace of change; this may be conservative, gradual or radical. Finally, there is the determinant of change: technology determinism, social determinism or contingency.

The value of the framework may not lie so much in its ability to provide accurate prediction, but in its potential for stimulating alternative scenarios of future Internet reporting which we believe are useful for interested parties in their policy-making. The framework can also be used to categorize existing and future studies of Internet reporting. However, theorizing is inevitably an iterative process. Thus further studies are needed to validate the framework and investigate the extent to which it is useful.

\section{REFERENCES}

AMERICAN ACCOUNTING ASSOCIATION (1991): "The Report of the Committee on Accounting and Auditing Measurements 1989-1990", Accounting Horizons, 5 (3): 81-101.

AOUN, B.. (1996): Agent Technology in Electronic Commerce and Information Retrieval on the Internet. http:/www/scu.edu.au/spnsored/ausweb/ausweb96/tech/ aoun/paper.htm.

ASHBAUGH, H.; JOHNSTONE, K. M.; WARFIELD, T. D. (1999): “Corporate Reporting on the Internet", Accounting Horizons, 13(3):241-258.

BALDWIN, A.; WILLIAMS, S. (1999): "The Future of Intelligent Agents in European Financial Reporting”, European Accounting Review, 8 (2):303-319.

BARKER, R. (1999): Financial Reporting and Share Prices: The Analysts' and Fund Managers'Views. PricewaterhouseCoopers. London.

BEATTIE. V. (1999): Business Reporting: An Inevitable Change? Institute of Chartered Accountants of Scotland. Edinburgh. 
BURCHELL, S.; CLUBB, C; HOPWOOD, A.; HUGHES, J.; NAHAPIET, J. (1980): "The Roles of Accounting in Organizations and Society", Accounting, Organizations and Society, 5 (1):5-27.

BRITISH BROADCAST COMPANY (BBC) (1999): Online Share Dealing Triples. Thursday, November 18. http: news.bbc.co.uk/hi/english/business/the_economy/ newsid_526000/526414.stm

BURY, L. (1999): “On Line and on Time”, Accountancy, August: 28-29.

Canadian Institute of Chartered Accountants (CICA) (1999): Continuous Auditing, An CICA/AICPA Research Study. CICA. Toronto.

CAPLAN, J. (2001): A Virtual Close: As Easy as One, Two, Three?' CFO.com, March 8. http:/ www.cfo.com/Pge Channel Article Detail/1,4635,3|15|AD|2213|12,00. htm

CAROL UK (1999): Update on Internet Best Practice for Annual Reporting, March. http://www.carol.co.uk/hotnews.html\#latest_edition.

CLICKZ.COM (2004): Population Explosion! http:/www.clickz.com/stats/big picture/geographics/article.php/151151.

CORRIGAN, L. (1997); “Annual Shareholder's Meetings Go Online”, The Motley Fool's Rogue. http:// www.fool.com/Rogue/1997/Rogue970822.htm.

COURTIS, J. (2000): "Expanding the Future Financial Corporate Reporting Package", Accounting Forum, 24 (3): 248-263.

CUSHING, B. (1989): "On the Feasibility and Consequences of a Database Approach to Corporate Financial Reporting”, Journal of Information Systems, Spring: 29-52.

DEBRECENY, R.; GRAY, G. (1999): "Financial Reporting on the Internet and the External Audit”, European Accounting Review, 8 (2): 335-350.

DEBRECENY, R.; GRAY, G.; BARRY, T. (1999): Accounting Information in a Networked World - Resource Discovery, Processing and Analysis. Paper presented the 1999 Annual Congress of the European Accounting Association, France. 
DEBRECENY, R.; GRAY, G. (2001): "The Production and Use of Semantically Rich Accounting Reports on the Internet: XML and XBRL", International Journal of AIS, (2): 47-74.

DEBRECENY, R.; GRAY, G. L.; RAHMAN, A. (2002): “The Determinants of Internet Financial Reporting. Journal of Accounting and Public Policy, 21: 371-394.

DELLER, D.; STUBENRATH, M.; WEBER, C. (1999): "A Survey on the Use of the Internet for Investor Relations in the USA, UK and Germany", European Accounting Review, 8 (2): 351-364.

DUNN, C. L.; MCCARTHY, W. E. (1997): 'The REAL Accounting Model: Intellectual Heritage and Prospects for Progress', Journal of Information Systems, 11(1): 31-51.

DUTTON, W. (ed.) (1996): Information and Communication Technologies: Vision and Realities. Oxford University Press. Oxford.

EDGE, D. (1994): “The Social Shaping of Technology", In Heap, N., Thomas, R., Einon, G., Mason, R., and Mackay, H. (eds.), Information Technology and Society. Sage. London.

ETTREDGE, M.; RICHARDSON, V. J.; SCOLZ, S. (2002): "Dissemination of Information for Investors at Corporate Web Sites", Journal of Accounting and Public Policy, 21:357-369.

ELLIS \& EVERARD PLC. (2001): Preliminary Results for the Year Ended 30 April 2000. http:/www.elliseverard.com.htm.

ELLIOTT REPORT. (1996): Effect of Information Technology on the Assurance Services Marketplace. Special Committee on Assurance Services of the American Institute of Public Certified Accountants. http:/www.aicpa.org/assurance/scas comstud/effect/index.htm.

E-MARKETER.COM (2003): Worldwide B2B Revenues to Pass One Trillion. http:/ www.eMarketer.com. 
ETFORCATS. (2001): Internet User Forecast by Country (updated july, 2001). http:/www.etforecasts.com/products/ES intusersv2.htm

ETTREDGE, M.; RICHARDSON, V. J.; SCOLZ, S. (2001): "The Presentation of Financial Information at Corporate Web Sites", International Journal of AIS, (2): 149-168.

FINANCIAL ACCOUNTING STANDARDS BOARD (FASB) (2000): Business Reporting Research Project: Electronic Distribution of Business Reporting Information. Steering Committee Report Series. http:/www.fasb.org.

GOWTHORPE, C.; FLYNN, G. (1997): "Reporting on the Web: The State of the Art", Accountancy, August: 68-69.

GREEN, G.; SPAUL, B. (1997): "Digital accountability", Accountancy, May: 64-65.

HOWCROFT, D.; FITZGERALD, B. (1998): From Utopia to Dystopia: The Twin Faces of the Internet. http://www.bi/no/dep2/infomgt/wg82-86/proceedings/tableof-contents.htm.

INSTITUTE OF CHARTERED ACCOUNTANTS IN ENGLAND AND WALES (ICAEW) (1998): Prototype PLC.. ICAEW and the Centre for Tomorrow's Company, London.

JENKINS REPORT. (1994): Improving Business Reporting - A Customer Focus. Special Committee on Financial Reporting of the American Institute of Public Certified Accountants. http://www.rutgers.edu/accounting/raw/aicpa/business/ main.htm.

JENSEN, R.E.; XIAO, J.X. (2001): "Customized Financial Reporting, Networked Databases and Distributed File Sharing”, Accounting Horizons, 15 (3): 209-222.

KOGAN, A., SUDIT, F.; VASARHELYI, M. (1998): Some Auditing Implications of Internet Technology. http:www.rutgers.edu/accounting/raw/miklos/tcon3.htm. 
LYMER, A. (1997): "The use of the Internet in company reporting: A survey and commentary on the use of the WWW in corporate reporting in the UK", Journal of Financial Information Systems. http:/www.shu.ac.uk/schools/fsl/fisjnl//vol1996 pprs1997/lymer97.htm

LYMER, A.; DEBRECENY, R.; GRAY, G. L.; RAHMAN, A. (1999): Business Reporting on the Internet. IASC. London.

JUDD, E. (1998): “My Place or Yours?” The Internet Relations Magazine. http:// www.irmag.com/feature.asp?articleID=636

JUDD, E. (2000): “eVoting, 2000”, The Internet Relations Magazine. http:/ www. irmag.com/feature.asp?articleID $=815$

MCCARTHY, W. E. (1982): "The REA accounting model: A Generalized Framework for Accounting System in A Shared Data Environment", The Accounting Review, July: 554-578.

NETWATCH. (1999): An International Survey of the Internet. http://acnielsen. com/products/reports/netwatch/index.htm.

NUA.COM. (2002): How Many Online? http:/www.nua.com/surveys/how many online/ index.htm

SANDERS, M. R.; KAFKA,S. J.; HURD, L. (2001). eBusiness Propels Productivity. http:// www.forrester.com.

SCHNEIDER, G.; BOWEN, P.L. (1997): “User-Customized Financial Reporting: The Potential of Database Accounting and the Internet", Proceedings of Pacific Asia Conference on Information Systems, April: 91-97.

SHU, L. J. (2001); Global B2B Commerce Forecast: Growth Pauses, but Expansion is on the Horizon. http:/www.gartnerg2.com.

SOLOMONS, D. (1978): "The Politicization of Accounting", Journal of Accountancy, Nov.: 65-72.

SORTER, G. (1969): “An 'Events' Approach to Basic Accounting Theory”, The Accounting Review, January: 12-19. 
SPAUL, B. (1997): Corporate Dialogue in the Digital Age. ICAEW, London.

TAYLOR, S. (1998): Web Sites - A missed opportunity? Business Briefing. Institute of Chartered Accountants in England and Wales, London.

TRITES, G. (1999): The impact of technology on financial and business reporting. Research study for the Canadian Institute of Chartered Accountants. Toronto.

UPTON, W. S. (1998): "The Internet and Financial Information - Is There a Future Here?" Accounting \& Business, June: 28-30.

WALLMAN, S. (1995): "The Future of Accounting and Disclosure in an Evolving World: The Need for Dramatic Changes", Accounting Horizons, 9(3): 81-91.

WALLMAN, S. (1997): "The Future of Accounting and Financial Reporting, Part Five: 'Access' Accounting”, Accounting Horizons, 11(2): 103-116.

XIAO, Z.; DYSON, J. R.; POWELL, P. (1996): "The Impact of Information Technology on Corporate Financial Reporting: A Contingency Perspective", The British Accounting Review, 28 (3): 203-227.

XIAO, Z.; JONES, M.; LYMER, A. (2002): Immediate Trends in Internet Reporting. The European Accounting Review, 11(2): 245-275.

XIAO, Z.; YANG, H.; CHOW, C. (2004): "Patterns and Determinants of InternetBased Corporate Disclosure in China”, Journal of Accounting and Public Policy, 23(3): 191-225.

ZEFF, S. (1978): "The Rise of "Economic Consequences"”, The Journal of Accountancy, December: 57-63. 


\section{APPENDIX 1: THE EXPERT PANEL}

\begin{tabular}{|c|c|c|}
\hline Experts & Position & Expertise \\
\hline $\begin{array}{l}\text { Academic } \\
\text { A }\end{array}$ & $\begin{array}{l}\text { Professor at an old university } \\
\text { in accounting and information } \\
\text { systems }\end{array}$ & $\begin{array}{l}\text { Active researcher into Internet and leader of several } \\
\text { projects; developed Web sites, published related articles } \\
\text { in leading journals }\end{array}$ \\
\hline $\begin{array}{l}\text { Academic } \\
\text { B }\end{array}$ & $\begin{array}{l}\text { Principal lecturer in accounting } \\
\text { and auditing at an new } \\
\text { university }\end{array}$ & $\begin{array}{l}\text { Auditing, Financial reporting, Internet reporting with } \\
\text { publications in leading journals }\end{array}$ \\
\hline Auditor A & $\begin{array}{l}\text { Partner and national director of } \\
\text { assurance and advisory services } \\
\text { of a "Big 5" audit firm }\end{array}$ & $\begin{array}{l}\text { Technical partner concerned with financial reporting, } \\
\text { Internet user, member of the UK Accounting Standards } \\
\text { Board }\end{array}$ \\
\hline Auditor B & $\begin{array}{l}\text { Head of financial reporting unit } \\
\text { of a top } 20 \text { UK auditing firm }\end{array}$ & Auditing and financial reporting \\
\hline Auditor $C$ & $\begin{array}{l}\text { Senior partner of a "Big } 5 \text { " } \\
\text { audit firm }\end{array}$ & $\begin{array}{l}\text { Corporate reporting innovation, valuation, Internet- } \\
\text { based corporate reporting, published influential works }\end{array}$ \\
\hline $\begin{array}{l}\text { Preparer } \\
\text { A }\end{array}$ & $\begin{array}{l}\text { Director of corporate affairs of } \\
\text { a top } 100 \text { UK company }\end{array}$ & $\begin{array}{l}\text { Investor relations, developed corporate Web site, delivery } \\
\text { of financial information via the Internet }\end{array}$ \\
\hline $\begin{array}{l}\text { Preparer } \\
\text { B }\end{array}$ & $\begin{array}{l}\text { Vice president and group chief } \\
\text { accountant of a top } 100 \mathrm{UK} \\
\text { company }\end{array}$ & $\begin{array}{l}\text { Financial reporting, regulatory filings, and electronic } \\
\text { filings }\end{array}$ \\
\hline $\begin{array}{l}\text { Preparer } \\
\text { C }\end{array}$ & Director of corporate finance & $\begin{array}{l}\text { Corporate reporting, Internet user, member of the UK } \\
\text { Accounting Standard Board }\end{array}$ \\
\hline $\begin{array}{l}\text { Preparer } \\
\text { D }\end{array}$ & $\begin{array}{l}\text { Deputy finance director of a } \\
\text { top } 100 \mathrm{UK} \text { company, former } \\
\text { partner with a "Big } 5 \text { " audit } \\
\text { firm }\end{array}$ & Internet-based information services and auditing \\
\hline $\begin{array}{l}\text { Preparer } \\
\text { E }\end{array}$ & $\begin{array}{l}\text { Chief financial accountant of a } \\
\text { top } 100 \text { UK industrial company }\end{array}$ & $\begin{array}{l}\text { Frequent user of the Internet, company intranet } \\
\text { development, and responsible for corporate reporting }\end{array}$ \\
\hline $\begin{array}{l}\text { Regulator } \\
\text { A }\end{array}$ & $\begin{array}{l}\text { Corporate finance manager and } \\
\text { Industrial secondee }\end{array}$ & $\begin{array}{l}\text { Business process redesign issues, the technology sector, } \\
\text { corporate governance, financial reporting, legislation, } \\
\text { and use of electronic tools }\end{array}$ \\
\hline $\begin{array}{l}\text { Regulator } \\
\text { B }\end{array}$ & Policy and planning officer & $\begin{array}{l}\text { Information technology policy and planning, delivery of } \\
\text { corporate information via the Internet }\end{array}$ \\
\hline $\begin{array}{l}\text { Regulator } \\
\text { C }\end{array}$ & $\begin{array}{l}\text { Head of IT management and } \\
\text { information services }\end{array}$ & IT management, control and security \\
\hline $\begin{array}{l}\text { Regulator } \\
\text { D }\end{array}$ & Assistant technical director & $\begin{array}{l}\text { Accounting standard setting, Web site development and } \\
\text { user of the Internet }\end{array}$ \\
\hline $\begin{array}{l}\text { Regulator } \\
\text { E }\end{array}$ & $\begin{array}{l}\text { Division manager, in charge of } \\
\text { equities }\end{array}$ & $\begin{array}{l}\text { Stock exchange regulation of financial reporting, liaison } \\
\text { with standard setters }\end{array}$ \\
\hline $\begin{array}{l}\text { Regulator } \\
\text { F }\end{array}$ & Webmaster of the organisation & $\begin{array}{l}\text { Accounting standard setting, Web site development and } \\
\text { management, certified public accountant, past chief } \\
\text { executive officer and university professor }\end{array}$ \\
\hline User A & Financial analyst & Investment analysis \\
\hline User B & Development director & $\begin{array}{l}\text { Financial reporting, Internet-based corporate } \\
\text { communication strategy, developed one of the largest on- } \\
\text { line annual report portal sites, and consultant to leading } \\
\text { companies (e.g., BP, TI Group and Cookson) on the use } \\
\text { of the Internet }\end{array}$ \\
\hline User C & Managing director & Investor relations, shareholder voting, on-line voting \\
\hline User $C$ & Consultant and researcher & $\begin{array}{l}\text { Management compensation plans, employee share } \\
\text { scheme, human resource management, involved in setting } \\
\text { up Web sites and developing Internet-based projects }\end{array}$ \\
\hline
\end{tabular}

Note: Three experts whose details are in italics did not respond to the survey reported in this paper. 